\title{
Editorial
}

\section{Pain Physician: An Emerging Journal of Interventional Pain Management in the New Millennium}

Howard Smith, MD, Bert Fellows, MA, and Laxmaiah Manchikanti, MD

$\mathrm{n}$ the view of George Bernard Shaw, the famous playwright, "every profession is a conspiracy against the laity." Whether this is true or not for each medical specialty, it has been true for pain management or pain medicine in general, but it is certainly not true for interventional pain management. Emerging as a leader in this newly recognized specialty, the American Society of Interventional Pain Physicians (ASIPP) has embodied Ronald Reagan's philosophy that, ... " there is no limit to what a man can do or where he can go if he doesn't mind who gets the credit." And, the greatest vehicle of ASIPP for communicating its values, goals, and commitment to progress has been their premier, bi-monthly, peer-reviewed professional journal, Pain Physician, which, since its inception, has evolved into a dynamic, clinical and practical journal bridging the gap between clinical practice and academic medicine.

\section{Humble Beginnings}

The American Society of Interventional Pain Physicians, the largest organization representing interventional Pain Physicians, with the goal of preserving interventional pain management into the future, was originally incorporated in November 1998 as the Association of Pain Management Anesthesiologists (AOPMA). In 1998 there was no recognition for interventional pain management and it was not a specialty despite a growing number of so-called pain clinics in the United States, various organizations representing Pain Physicians and practitioners, and pain management journals. At that time, interventional pain management suffered from a lack of proper recognition, coupled with misconceptions, malaise and apathy, resulting in a motivational deficiency syndrome among interventional pain physicians and leading to suspicion among healthcare administrative authorities and insurers.

Pain medicine in general, and interventional pain management in particular, was full of conflicting and uncertain information with no clearly focused leadership to sort out, clarify, and organize appropriate information and to maintain and protect patient access to services. Pain medicine had been largely dominated and essentially taken over by physicians who believed in the biopsychosocial model, utilizing predominantly psychological or functional approaches. Interventions, although seen

From: American Society of Interventional Pain Physicians, Paducah, Kentucky

Dr. Smith is Editor-in-Chief of the Pain Physician journal. Bert Fellows is Managing Editor of the Pain Physician journal.

Dr. Manchikanti is founder of the Pain Physician journal.

Address Correspondence: Howard Smith, MD 47 New Scotland Avenue Albany NY 12208

E-mail: editor@painphysicianjournal.com 
as an integral part of chronic pain was considered to be only peripheral. For many, pain is viewed as always being subjective and as such is always a psychological state. At the same time, interventional pain management is viewed as a procedural specialty unlike the field of pain medicine, which is considered to be a non-procedural specialty (1-3). There was much criticism of interventional pain management, which at times was an accurate reflection of the state of interventional pain management, because of excessive use and abuse of the various interventions by some, by lack of demonstration of medical necessity, and by lack of outcomes, and lack of cost effectiveness. This criticism not only stemmed from non-physicians, but also from physicians of all walks, including pain medicine. Even today, much of the controversy continues stemming from the actions of short-sighted pain specialists with different philosophies who have failed to understand and assimilate economic and medical realities or who are overly aggressive in their attitudes.

During this turmoil, every specialty wanted to grab interventional pain management, but was not willing to provide any substantial support. Almost all of the studies being published had negative outcomes, and opponents would argue that there were no well conducted positive studies - they were all negative. Consequently, for lack of positive outcome studies, pain medicine journals were primarily interested in biopsychosocial approaches; spine and orthopedic journals were interested only in surgical manuscripts, and there was no place for interventional pain management literature - specifically, positive ones.

A fledgling society with a membership of 250 , the Association of Pain Management Anesthesiologists founded by Laxmaiah Manchikanti, MD, embarked on its own journal, Pain Physician, despite the laughter, discouragement, and ridicule of major organizations and experts. Thus, Pain Physician took birth with extreme difficulty provoking medical and political friction and opposition. The first issue was published in October 1999, and assumed the task of creating a forum for scientific and clinical advances made in interventional pain management, and also to advance the purposes and goals of the sponsoring organization (at that time still named the Association of Pain Management Anesthesiologists), which were to continue to play an active role in regulatory changes, practice compliance, and practice management in an increasingly complex healthcare environment.

The transformation following the initial issue also proved to be contentious. The second issue of Pain Physician, published in January of 2000 (The Millennium Issue) contained peer reviewed interventional pain management guidelines - widely accepted by most practitioners, but felt by some sources to be controversial. However, through the tireless efforts of ASIPP, the transformation was made easier by obtaining recognition of interventional pain management as its own specialty, thus providing a clear identity as well as representation at the state and national levels (4). Interventional pain management, which had been an obscure entity, not only received specialty designation but also received a concrete definition which identified it as a medical specialty (5). In further clarifying the new specialty, the National Uniform Claim Committee (NUCC) defined interventional pain management as, "the discipline of medicine devoted to the diagnosis and treatment of pain related disorders principally with the application of interventional techniques in managing subacute, chronic, persistent, and intractable pain, independently or in conjunction with other modalities of treatments." Subsequently, to further bolster and clarify its new identity as a specialty, interventional techniques themselves received a definition from the Medicare Payment Advisory Commission (MedPAC) (6). MedPAC defined interventional techniques as, "minimally-invasive procedures including: percutaneous precision needle placement, with placement of drugs in targeted areas or ablation of targeted nerves; and some surgical techniques for the diagnosis and management of chronic, persistent or intractable pain such as laser or endoscopic diskectomy, intrathecal infusion pumps and spinal cord stimulators." Finally, in another major victory for interventional Pain Physicians, the specialty of interventional pain management was bolstered by mandatory representation as the 34th specialty on the Carrier Advisory Committees (7).

At a Meeting in Honolulu on November 10-13, the American Medical Association (AMA) House of Delegates adopted a resolution that the "interventional pain management of patients suffering from chronic pain constitutes the practice of medicine" -- and by inference, should not be conducted by certified nurse anesthetists or any health care providers other than physicians.

In the modern day medical environment, as with the composition of interventional pain management, an interventional pain practitioner continues to provide an immense variety of therapeutic choices. Be- 
cause of this, it has become extremely difficult for interventional pain physicians to keep pace with the specific developments in interventional pain management and also to translate this into evidence-based interventional pain management. Further, physicians practicing interventional pain management now can refer to themselves as interventional pain physicians without referring to their heredity such as pain management anesthesiologist, pain management neurologist, pain management psychiatrist, pain management radiologist, pain management physiatrist or pain management neurosurgeon, etc. While on the one hand this spirit of unity between various specialties has produced an environment that is conducive to scientific and clinical innovations, along with compliance with regulations, some are still trying to maintain their separate identity even though what they practice is interventional pain management and describe themselves as spine interventionalists, interventional physiatrists, interventional radiologists, etc. Figure 1 illustrates evolution of Pain Physician as a journal of emerging specialty interventional pain management.

\section{Past and Presenut}

Following the ground-breaking second issue of Pain Physician with the first ASIPP Guidelines in January of 2000, the journal continued its growth and evolution as it matured into the premier stature that it holds today. In April 2002, Curtis W. Slipman, MD, was appointed as the Editor-in-Chief, with Bert Fellows, MA, continuing as the Managing Editor (8). Efforts were initiated to broaden the journal beyond its origins in anesthesiology to include other primary disciplines with an expanded editorial advisory board and by increasing the number of publications, thus fostering interdisciplinary interest in the journal. At the same time that the clinical/scientific content of Pain Physician was improving, there were simultaneous cosmetic changes made in the format as well in the years 2000, 2002, 2003, 2004, and 2006 (Fig. 1).

An additional step in the evolution occurred in 2004 when Mark V. Boswell, MD, PhD, became the new Editor-in-Chief (9). During these 4 years, Pain Physician further moved into the challenging world of healthcare crisis in the United States. The changes reflecting maturity included rather bold changes on occasion with transformation of the journal from 4 issues per year to 6 issues and listing on EMBASE in 2002, followed by Index Medicus, Medline, and PubMed with approval in March 2006.
Thus, we welcome 2008 and the new editor-inchief, Howard Smith, MD, from Albany Medical College, Albany, New York. In our quest to provide the entire membership of ASIPP and the interventional pain management community, the Pain Physician is not only listed on Medline, Index Medicus, PubMed, and EMBASE, but is available online at no cost.

\section{Future}

Pain Physician must continue to achieve new heights and encourage the submission of large multicenter well-designed studies demonstrating statistically significant effects on various "quality of life" outcome measures. However, interventional pain management should not only strive to provide quality literature to guide evidence-based practice, but additionally should be involved with preclinical and clinical research to advance the field and improve current practice status.

The future of interventional pain management seems particularly exciting and there is much to be done. Developing future diagnostic and therapeutic strategies in efforts to continually advance the field is essential. Future nerve blocks may be performed with a combination of QX-314, a lidocaine derivative and capsaicin, instead of traditional anesthetics (e.g., bupivacaine). Binshtok and colleagues (10) demonstrated that capsaicin serves to "stent" open TRPV1 channels, allowing QX-314 to pass through and selectivity block the cells activity. Thus, this combination of agents may possess the ability to block nociceptive neurons without affecting other sensory or motor neuron functions.

Furthermore, new agents/techniques/modalities may be useful instead of or in addition to more traditional agents/techniques/modalities. Initial results from the evaluation of tumor necrosis factor-alpha inhibitor via intradiscal administration for chronic discogenic low back pain or lumbosacral radiculopathy have been disappointing (11). However, there are many other potential therapies awaiting evaluation including: antioxidants, glial inhibitors (e.g. minocycline), intrathecal MEK inhibitors (e.g. PD 98059) or p38 MAPK inhibitors, carbamylated erythropoietin and/or gene therapy to augment the endogenous anti-inflammatory cytokine, interleukin-10 (IL-10).

In the future, "designer" combinations tailored to specific populations where opioids could yield suboptimal analgesia may be available. For example, combined IL-4 (or IL-4 receptor enhancer) and opioid in 


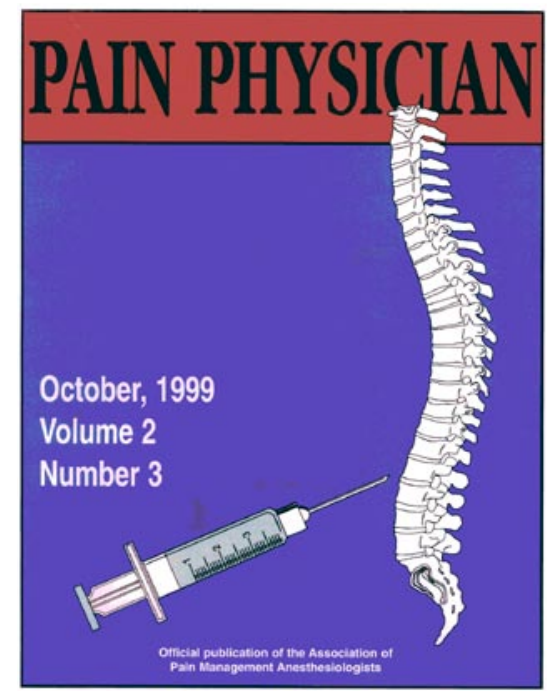

First issue

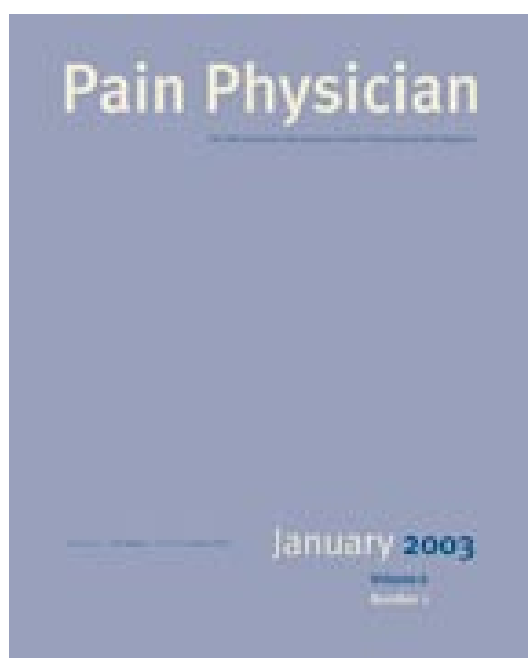

First issue 2003

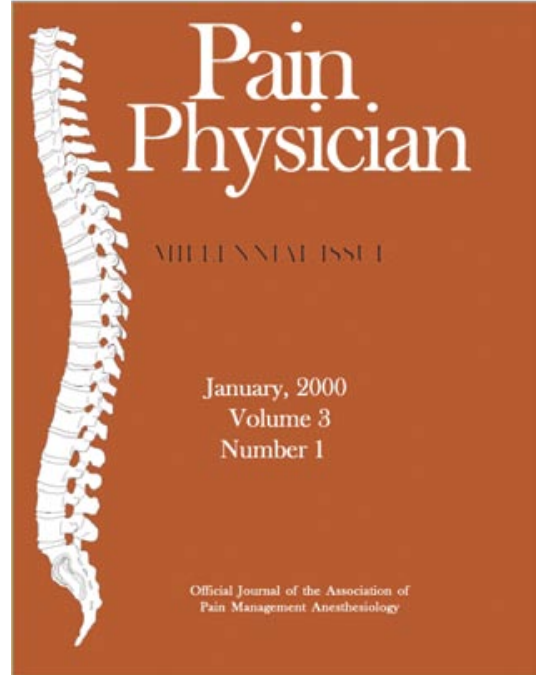

First issue 2000

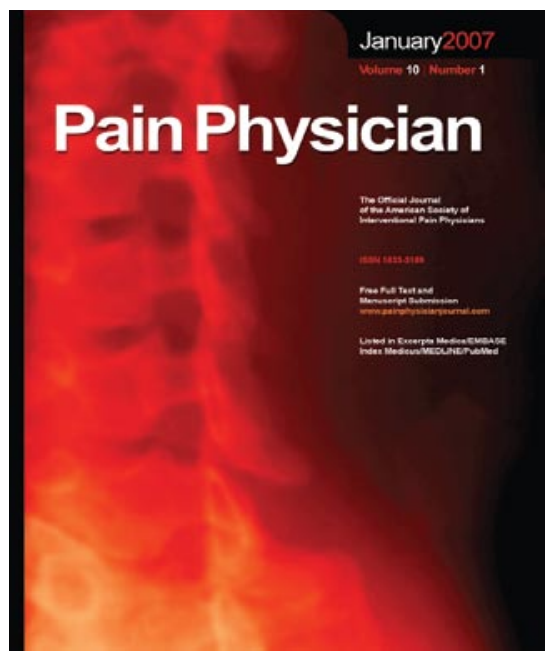

First issue 2007

Fig. 1. Illustration of the evolution of Pain Physician

those patients with diminished functional activity of IL-4 and/or reduced opioid receptor expression (IL-4 induces and upregulates the transcription of mu and delta opioid receptors via a STAT6-binding site (12, 13).

Finally, interventional approaches to pain management should not be practiced in a "vacuum". Op- timal outcomes for most patients with complex pain problems likely involve a "melting pot" of treatment approaches including: behavioral medicine approaches, physical medicine approaches, pharmacologic approaches, neuromodulation approaches, surgical approaches, as well as interventional approaches. Interventional pain medicine specialists should be uti- 


\section{Acknowledgments}

lizing these other approaches, when appropriate, whether they are contained within the pain management clinic "setting" or not.
The authors wish to thank Tonie D. Hatton and Diane E. Neihoff, transcriptionists, and Pya Seidner for their assistance in preparation of this manuscript.

\section{References}

1. Manchikanti L. State of interventional pain medicine. Pain Physician 2000; 3:241-255.

2. Manchikanti L. Interventional Pain Physician. What's in a name? Pain Physician 2000; 3:132-138.

3. Morris DB. An invisible history of pain: Early 19th century Britain and America. Clin J Pain 1998; 191-196.

4. US Department of Health and Human Services. Centers for Medicare and Medicaid Services (CMS) Medicare Carriers Manual. Part 3 - Claims Process. Change Request 2337, Section 2207, Coding Physician Specialty. November 1, 2002. http://d1724106.u29.globalhosting.com/News\%2odocuments/ r1779b.pdf

5. The National Uniform Claims Committee. Specialty Designation for Interventional Pain Management- 09.

6. Medicare Payment Advisory Commis- sion. 2001. Report to the Congress: Paying for interventional pain services in ambulatory settings. Washington, DC: MedPAC. December.

7. US Department of Health and Human Services. Centers for Medicare and Medicaid Services (CMS) Manual System. Pub. 100-08 Medicare Program Integrity. Inclusion of Interventional Pain Management Specialists on Carrier Advisory Committee (CAC) Membership. Change request 3721. March 4, 2005. http://www.cms.hhs.gov/transmittals/ downloads/R106PI.pdf

8. Slipman CW. Pain Physician embraces the future. Pain Physician 2002; 5:119120.

9. Boswell MV. New beginnings. Pain Physician 2004; 7:1.

10. Binshtok AM, Bean BP, Woolf CJ. Inhibition of nociceptors by TRPV1-mediated entry of impermeant sodium channel blockers. Nature 2007; 449:607-610.

11. Cohen SP, Wenzell D, Hurley RW, Kurihara C, Buckenmaier CC 3rd, Griffith S, Larkin TM, Dahl E, Morlando BJ.. A double-blind, placebo-controlled, dose-response pilot study evaluating intradiscal etanercept in patients with chronic discogenic low back pain or lumbosacral radiculopathy. Anesthesiology 2007; 107:99-105.

12. Kraus J, Borner C, Giannini E, Höllt V. Regulation of mu-opioid receptor gene transcription by interleukin- 4 and influence of an allelic variation within a STAT6 transcription factor binding site. J Biol Chem 2001; 276:43901-43908.

13. Börner C, Wöltje M, Höllt V, Kraus J. STAT6 transcription factor binding sites with mismatches within the canonical 5'-TTC...GGA-3' motif involved in regulation of delta- and mu-opioid receptors. J Neurochem 2004; 91:1493-1500. 